\title{
O PROCESSO DE ESCRITA LITERÁRIA E A COEMERGÊNCIA DA OBRA DE ARTE E DO AUTOR
}

THE LITERARY WRITING PROCESS AND THE CO-EMERGENCY OF THE AUTHOR AND THE WORK OF ART

EL PROCESO DE ESCRITURA LITERARIA Y LA CO-EMERGENCIA DE OBRA DE ARTE Y AUTOR

Virginia Kastrup*

Veronica Gurgel

\begin{abstract}
RESUMO
A escrita e o processo de criação em Literatura têm sido objeto de investigação em diferentes campos do conhecimento, entre os quais destacam-se a crítica literária e os saberes psi, como a Psicanálise, a Psicologia cognitiva e a Psiquiatria. Nesses campos, abordagens de cunho biográfico e psicologizante foram, por vezes, predominantes. O objetivo deste artigo é analisar as críticas a tais abordagens e buscar alternativas à relação causal entre autor e obra. Com base em Barthes, Foucault e Chartier, procuramos evidenciar que a autoria não é natural, mas surgiu no século XVII, repercutindo nas análises literárias. A partir de Blanchot e Dewey, argumentamos que o escritor se deixa guiar pelo que percebe: é escritor e leitor, simultaneamente. Com Varela, Thompson e Rosch, concluímos que a obra e o autor são efeitos de um mecanismo de coemergência, sendo engendrados de um mesmo processo de criação literária.
\end{abstract}

Palavras-chave: Autor. Escrita literária. Coemergência.

\begin{abstract}
Writing and the process of creation in literature have been the subject of research in different fields of knowledge, among which stand out literary criticism and psy-knowledge, such as psychoanalysis, cognitive psychology, and psychiatry. In these fields, biographical and psychologizing approaches were sometimes predominant. The purpose of this article is to analyze the criticism of such approaches and seek alternatives to the causal relationship between author and work. Based on Barthes, Foucault and Chartier we mean to set into evidence that the authorship is not natural, but arose in the XVII century, causing consequences on literary analysis. Based on Blanchot and Dewey, we argue that the writer is guided by what he/she perceives:
\end{abstract}

Texto recebido em 22 de setembro de 2016 e aprovado para publicação em 19 de junho de 2017.

*Doutora em Psicologia Clínica pela Pontifícia Universidade Católica de São Paulo (PUC SP) e docente no Instituto de Psicologia da Universidade Federal do Rio de Janeiro (UFRJ).E-mail: virginia.kastrup@gmail.com.

** Doutora em Psicologia pelo Programa de Pós-Graduação em Psicologia da UFRJ (PPGP/UFRJ) e docente no Centro Universitário IBMR. E-mail:vgurgel@gmail.com. 
he/she is the writer and reader simultaneously. With Varela, Thompson and Rosch, we conclude that the work of art and the author are effects of a mechanism of co-emergency, that is, both are engendered by the same process of literary creation.

Keywords: Author. Literary writing. Co-emergency.

\section{RESUMEN}

La escritura y el proceso de creación en literatura han sido objetos de investigación en diferentes campos del conocimiento, entre ellos se destacan la crítica literaria y los saberes psi, como el psicoanálisis, la psicología cognitiva y la psiquiatría. En estos campos, los enfoques biográficos y psicologizantes fueron muchas veces predominantes. El objetivo de este artículo es analizar las críticas a dichos enfoques y buscar alternativas a la relación causal entre autor y obra. Basados en Barthes, Foucault y Chartier, buscamos demostrar que la autoría no es natural: ella surgió en el siglo XVII y se refleja en el análisis literario, que comenzó a considerar la biografía del autor como medio de interpretación de la obra. Basados en Blanchot y Dewey, argumentamos que el escritor necesita ser guiado por lo que percibe: ser escritor y lector de forma simultánea. Con Varela, Thompson y Rosch concluimos que la obra y el autor son efectos de un mecanismo de coemergencia, y son engendrados a partir de un mismo proceso de creación literaria.

Palabras clave: Autor. Escritura literaria. Co-emergencia.

\section{ESCRITA E CRÍTICA LITERÁRIA: AUTORIA E INVENÇÃO}

Q uando os campos psi tratam do tema da criação literária na Psicologia, é habitual que os autores adotem uma postura psicologizante, que busca encontrar nos textos reflexos da vida pessoal de seus autores. Essa postura remorra a Freud (1928/2014) $)^{1}$ e psicanalistas como Jones (1970) e Helson (1977), surgindo ainda na psiquiatria, com Storr (2013), e na Psicologia cognitiva, com Piirto (1998; 2002; 2009), Kaufman (2002) e Kaufman \& Kaufman (2009). A obra seria fruto dos desejos inconscientes ou das vontades conscientes de um autor que antecederia esse processo. Seguindo em uma outra direção, Ferreira (2011; 2014), Pantaleão (2013) e Cabral (2006) apontam para novas formas de compreender a relação entre autor, obra, leitor.

Escritores como Proust (1988) criticaram duramente essa posição, que parte do pressuposto de que o escritor é uma unidade que precede e orienta a obra,

\footnotetext{
1 A primeira data indica o ano de publicação da obra, e a segunda, a edição consultada pelo autor, a qual somente será pontuada na primeira citação da obra no texto. Nas seguintes, será registrada apenas a data de publicação original.
} 
sendo o total e único responsável por ela. No entanto, como Blanchot (2011a; 2011b) e Deleuze e Guattari (1993) indicam, todo texto é uma produção coletiva. Seja um diário pessoal, seja um artigo acadêmico, o texto não é fruto de uma subjetividade pessoal e individualizada. Essa posição destaca que a própria subjetividade resulta de um processo coletivo de produção, que entrecruza vetores heterogêneos (econômicos, culturais, históricos, etc.). Desse modo, contrapóese a uma concepção de que o indivíduo é a origem explicativa para os fenômenos psicológicos, afirmando a necessidade de compreendermos a subjetividade como efeito de certas práticas (Gurgel, 2015).

Essa questão surge, em grande parte, na fala de escritores como Clarice Lispector, Truman Capote, Javier Marías, Mario Vargas Llosa, Ricardo Piglia, Cristóvão Tezza, Milan Kundera e Ernest Hemingway. Estes, e muitos outros, forçam-nos a pensar a respeito da própria escrita e das relaçóes entre autor e obra. Seria ela paternal, umbilical (como diria Lispector)? Ou, pelo contrário, fugiria às rédeas do escritor, apontando para novos rumos e sentidos?

Este estudo tem como objetivo discutir o processo de escrita literária com base em um enfoque que aponta para a desindividualização do autor, tema que vem, aos poucos, ganhando atenção por parte da Psicologia. Para tanto, este artigo se divide em duas partes. Na primeira, tomamos como base as ideias de Barthes (1988), Foucault (2009) e Chartier (1999; 2012) para evidenciar que a noção de autor é relativamente recente e, de modo algum, natural. Procuramos indicar de que maneira essa concepção surgiu historicamente e que os textos não devem ser entendidos como frutos de uma entidade individual (o autor). Assim, expomos algumas abordagens que se contrapõem ao biografismo, movimento da crítica literária que interpreta os textos com base no pressuposto da unidade do autor.

Em um segundo momento, tomamos como base Dewey (2010), Deleuze e Guattari (2014) para buscar entender o círculo inventivo da criação literária. Buscaremos mostrar que não devemos pensar a escrita como um processo controlado por um indivíduo, pois ela não é apenas uma expressão de um eu interior, mas um processo que produz subjetividade, que cria modos de ser e estar no mundo. Para tratarmos melhor essa relação, acompanhamos as reflexões de Dewey (2010) a respeito da experiência estética. Esse autor concebe o processo artístico como mais do que uma ação: ele também envolve a percepção. $\mathrm{O}$ escritor deve se deixar guiar por aquilo que escreve, e não simplesmente impor ao texto uma forma preconcebida. Por fim, com Rolnik (1996), Deleuze e Parnet (1998), Kastrup (2007) e Gurgel (2015), procuramos indicar que a escrita não é a transposição de uma história pessoal para um texto. Embora os elementos biográficos possam comparecer nas narrativas, eles sempre sofrem processos de 
invenção e reinvenção, o que implica sua transformação e a multiplicação de seus sentidos.

\section{O NASCIMENTO DA AUTORIA}

A noção de autor pode parecer, à primeira vista, natural e consensual, pois qualquer um pode escrever, publicar e assinar seu nome. Quando escrevo um texto, considero que sou responsável por ele. Por outro lado, se copio um texto produzido por outra pessoa e não lhe cito a autoria, incorro na prática do plágio, uma vez que, legalmente, o texto de outro só pode ser reproduzido com a devida atribuição de créditos. Assim, para que eu me torne um autor, é preciso que meus textos tenham um caráter original, que não sejam meras cópias das ideias de outros, que tenham alguma marca singular. Nenhuma dessas afirmações é novidade. Pelo contrário, elas parecem bastante triviais, e essa familiaridade aponta para o fato de que o autor é, ainda, um conceito pouco questionado em nossa cultura.

No entanto, segundo Foucault (2009), tanto na Antiguidade quanto na Idade Média, a tradição oral imperava. Nesse momento, não havia o conceito de autor, entendido como o responsável por uma obra, mas muitas versões, contadas por diferentes pessoas. Em cada versão, detalhes poderiam ser acrescentados ou omitidos, segundo o julgamento de quem a proferia. Com o surgimento da obra escrita, marcada por uma maior durabilidade, a figura do autor torna-se cada vez mais forte e naturalizada, de forma que, no século XIX, o foco da crítica literária passa a recair na figura do autor. $\mathrm{O}$ estudo da biografia passa a ser a mais importante chave de compreensão de sua obra, dando origem ao movimento de crítica denominado biografismo.

O biografismo buscava encontrar indícios da vida do autor no seu texto e, por outro lado, ajustar a obra aos conteúdos biográficos de quem a escreveu. O principal representante desse movimento foi o crítico francês Sainte-Beuve, que afirmava a necessidade de "entrar no autor, instalar-se lá dentro, produzi-lo em seus diversos aspectos” (Sainte-Beuve, 1829 apud Alves, 2014, p. 5). É nesse momento que o autor se torna o ponto de origem da obra, individualmente responsável por ela, supostamente controlando-a e orientando-a em razão da mensagem que deseja transmitir. Embora essa concepção ainda tenha grande força no senso comum, ela é constantemente criticada por diversos escritores. Segundo Capote (2011), muito pouco do que ele escreve é autobiográfico. Para Marías (2011), o mais importante não é o material biográfico, mas o filtro que se interpõe na passagem deste à literatura, destacando que, para o leitor, a 
verossimilhança das narrativas deve importar mais que a veracidade dos fatos. Segundo Llosa (2008), a ficção é justamente a vida que não existiu.

$\mathrm{Na}$ França da década de 1960, a compreensão da relação autor-obra se modifica com o surgimento de críticas ao conceito de autor, entendido como aquele que antecede e confere unidade e sentido à obra. Ao mesmo tempo, adensam-se as críticas ao biografismo, uma vez que esse tipo de interpretação pressupõe a existência de uma unidade de sentido no texto, orientada por uma outra unidade: a de um eu anterior, individual e coerente. Nesse momento, pensadores como Barthes (1988) e Foucault (2009) formulam questionamentos importantes a esse respeito. Em 1968, é publicado em francês $A$ morte do autor, texto em que Barthes (1988) faz uma crítica veemente ao modelo biográfico da crítica literária, que ainda estaria preocupado em juntar, com base em seus diários íntimos, a pessoa do escritor e sua obra. Barthes afirma que a figura do autor é uma criação moderna, coetânea ao surgimento do indivíduo. Desse modo, ele situa historicamente esse conceito, relativizando sua importância e destituindo-o do papel que lhe é frequentemente atribuído.

Opondo-se à crítica literária que busca as intenções veladas e prévias dos autores, Barthes afirma: "Supõe-se que o Autor alimenta o livro, quer dizer que existe antes dele, pensa, sofre, vive com ele; tem com ele a mesma relação de antecedência que um pai mantém com o seu filho" (Barthes, 1988, p. 69). No entanto, a linguagem fala por si mesma; não é mero veículo para a exposição de ideias, pensamentos ou sentimentos de um autor que a precede. Ao longo de seu texto, Barthes defende que a escritura é a destituição de toda origem, estando para além dos indivíduos, das pessoalidades. $\mathrm{O}$ texto de Barthes defende a desindividualização da obra literária, indicando a importância da performatividade ou da ação narrativa, muito mais do que o suposto "gênio" ou interioridade individual do escritor.

Ainda em $A$ morte do autor, Barthes (1988) se contrapõe ao autor como figura que antecede, nutre, orienta e direciona o texto. Em seu lugar, só haveria o texto escrito no aqui e agora. Em vez de autor, Barthes usa o termo scriptor para se referir a essa função ou posição do sujeito em um texto ou discurso. O scriptor não é um ponto originário a partir do qual os discursos são emanados. Pelo contrário, o scriptor emerge ao mesmo tempo em que o texto: não o antecede nem o ultrapassa (Castle, 2007). Além disso, de acordo com Barthes, um texto jamais é original. Para ele, o poder do scriptor (e do texto) consiste em mesclar diferentes escrituras, sendo a obra um emaranhado de citações e escrituras. E é por esse motivo, inclusive, que o texto não segue uma linha única em um sentido bem delimitado, mas se propaga em direções diversas. 
Essa ideia pode causar um estranhamento se compreendermos o escritor como aquele que produz um texto dotado de originalidade, fazendo algo que até então nunca foi feito. Barthes se opõe, justamente, à possibilidade de produzir algo "pela primeira vez" porque tudo já foi dito, de modo que o trabalho da literatura consiste na "escrita sobre a escrita", ou seja, é metalinguística. Conceber a escritura como um emaranhado de citações e de escrituras variadas permite um afastamento de interpretações psicologizantes da obra. Por um lado, porque o scriptor não é uma unidade que escreve com base em sua história pessoal. Por outro, pois a obra também não é plenamente coesa. A escritura não tem uma linha a ser seguida, linha que se expande e que segue um sentido predeterminado pelo "autor-deus", onisciente e onipotente. Não comporta um sentido último a ser desvelado, mas é um aglomerado de múltiplos discursos. Se não há "autordeus", não há ponto de origem ou nexo em tentar decifrar o sentido absoluto do texto. Isso não quer dizer, entretanto, que não haja qualquer compreensão possível. Pelo contrário, a escritura múltipla se oferece à compreensão por meio de diferentes linhas que podem ser seguidas, linhas pelas quais o texto pode ser desfiado; no entanto não há um sentido último ou mais profundo a ser descoberto. Para Barthes, a escritura propõe sentidos incessantemente, para, logo em seguida, deixá-los evaporarem, perderem-se.

\subsection{A função autor}

A conferência proferida por Foucault, em 1969, intitulada $O$ que é um autor?, questiona o relevo conferido a "quem" escreve (Foucault, 2009). Foucault e Barthes podem ser aproximados quanto à temática e à ênfase conferida ao caráter impessoal da linguagem, e por destituírem o papel do autor como origem do discurso. No entanto é preciso destacar certas diferenças existentes entre suas posiçōes, pois Foucault enfatiza a necessidade de entender de que forma e sob quais condições pode surgir um sujeito na ordem dos discursos e que funções ele pode exercer. Segundo ele, a noção de autor está conectada intimamente com a individualização das ideias, sendo uma das possíveis especificações da função sujeito; é desenvolvendo essa reflexão que ele chega à função autor (Foucault, 2009). Esta agrupa um número de escritos, conferindo-lhes unidade; cria relações de filiação ou de homogeneidade entre certos textos, excluindo, porém, outros; além disso, diz respeito às práticas que compõem a escrita e que produzem dois efeitos: por um lado, criam o autor como entidade individualizada, responsável por aquilo que escreve; por outro, estabelecem uma hierarquização dos discursos. Essa ideia, inclusive, é retomada por Foucault (2013) em A ordem do discurso, quando seu enfoque recai sobre a noção de autoria como uma ferramenta de controle do discurso. 
A função autor é resultado de operações complexas que conferem unidade e coerência a certos discursos, estabelecendo as maneiras pelas quais eles circulam em dada sociedade. Ela serve como um procedimento de controle do discurso. A função autor tem como efeito a produção de uma classificação dos discursos, permitindo atribuir a uma identidade individual um certo conjunto de textos. É desse conjunto, considerado mais ou menos coeso e relacionado a uma única função autor, que pode surgir a noção de obra.

Ao comentar a obra de Foucault, Chartier (2012) destaca que tal função é constituída, principalmente, de dois processos. O primeiro consiste em uma triagem dos textos, destacando dentre todos apenas aqueles aos quais essa função é atribuível. O segundo implica a construção da figura do autor e consiste na seleção dos traços pertinentes a sua caracterização. Para Foucault (2009), a função autor é marcada por quatro características: é objeto de uma apropriação penal; varia em diferentes tempos e locais; é efeito de operaçóes complexas; e, por fim, não corresponde a indivíduos reais.

Em primeiro lugar, a função autor é objeto de uma apropriação penal, estando relacionada com a possibilidade de sanção dos indivíduos que produzem discursos transgressores. Para Foucault (2009), a individualização das ideias está ligada à necessidade de legitimar certos discursos em detrimento de outros, por motivos políticos, econômicos e religiosos. A noção de autoria foi sendo construída conforme a obra passou a ser considerada como responsabilidade de um indivíduo específico. O nome do autor é que confere à obra autenticidade, distinção e um caráter de permanência, de modo que a função autor indica qual estatuto que cada texto deve adquirir. A importância da função autor pode ser atestada ao se verificar que a escrita de textos questionadores ou considerados inadequados frequentemente levava pessoas a serem julgadas como réus; era preciso punir aqueles que escreviam os textos indesejados. Chartier (2012) afirma que isso ocorreu entre os séculos XVI e XVII. Destaca ainda que no começo da era moderna são numerosas as condenações de autores de textos considerados política ou religiosamente transgressivos (Chartier, 1999). Porém, para condenar os responsáveis pelos textos, era preciso caracterizá-los como seus autores. Podemos encontrar as primeiras listagens sistemáticas de autores nos índices dos livros de autores proibidos do século XVI.

Em segundo lugar, a função autor não é exercida de modo homogêneo, variando de acordo com o tempo e o local. Em cada sociedade, os diferentes discursos têm relações diversas com a função autor. Para exemplificar essa característica, Foucault (2009) analisa uma mudança ocorrida por volta dos séculos XVII e XVIII. Na Idade Média, a veracidade dos textos científicos dependia do nome de seu autor (como "Hipócrates disse"); porém, posteriormente, tais discursos 
deixam de depender daquele que fala (é a ciência quem diz, e não o cientista). Por sua vez, o inverso teria ocorrido com os textos literários. Antes, anônimos, eles passaram a ser cada vez mais vinculados ao nome dos seus autores. Dessa forma, Foucault (2009) afirma que a função autor diz respeito ao modo como circulam e se articulam certos discursos em uma sociedade. Embora não recuse que a função-autor não atua de modo homogêneo, Chartier (2012) discorda de algumas colocações de Foucault com relação a esse ponto. Segundo ele, a função-autor não teria se apagado no discurso científico; além disso, a própria distinção entre textos literários e científicos lhe parece questionável.

Em terceiro lugar, para Foucault (2009), a função autor não surge de modo espontâneo, mas é fruto de operações complexas que visam a construir uma unidade. Como comenta Chartier (1999), isso implica uma dupla triagem: por um lado, trata-se de selecionar os textos que compóem a obra, pois nem tudo o que o se escreve é atribuído à função autor; por outro, nem tudo o que o autor faz é relevante para sua biografia, mas apenas aquilo que contribui para constituir uma unidade coerente e bem distinguível. Dessa maneira, o surgimento da função autor implica a seleção dos textos que compõem as obras, além do estabelecimento das suas chaves de leitura. Assim, tanto autor quanto obra surgem a partir de um mesmo tratamento que lhes é dispensado e que visa a criar certa homogeneidade e coesão.

Em quarto e último lugar, a função autor não corresponde, necessariamente, a um indivíduo real, mas a um agrupado mais ou menos coeso de textos. Para Foucault, o autor não deve ser entendido como o indivíduo que, de fato, escreveu uma obra, mas como um princípio de organização e agrupamento do discurso, responsável por sua unidade e coerência (Foucault, 2013). Acreditamos que podemos identificar dois tipos de casos em que essa característica se faz visível. A primeira situação é destacada por Foucault (2009) e implica agrupar textos escritos por diferentes pessoas sob um mesmo nome. Esse seria o caso de Hermes Trismegisto ou de Hipócrates, que não teriam existido como indivíduos reais, mas apenas como certo modo de ordenação de um conjunto de textos entre os quais haveria uma homogeneidade ou filiação.

O segundo caso pode ser exemplificado com os heterônimos de Fernando Pessoa, que têm suas biografias, datas e locais de nascimento bem definidos. Além disso, têm um nível relativamente constante de qualidade, coerência temática e unidade estilística e estão em relação com os personagens que lhe são contemporâneos (tendo, inclusive, mantido relações entre si). Nas palavras de Fernando Pessoa, para cada heterônimo ele deu uma 
Índole expressiva, e fez dessa personalidade um autor, com um livro, ou livros, com as ideias, as emoçōes, e arte dos quais, ele, o autor real (ou porventura aparente, porque não sabemos o que seja a realidade), nada tem, salvo o ter sido, no escrevê-las, o médium de figuras que ele próprio criou (Pessoa, 1974, p. 82)

Para Gagliardi (2010), as características atribuídas por Pessoa a cada um de seus heterônimos são mais do que meros detalhes. São ferramentas que nos ajudam a imaginar e os "traduzir em vida". Dessa forma, a poesia de Ricardo Reis e a de Alberto Caeiro compõem funçōes-autor distintas, embora não estejam vinculadas a pessoas reais distintas e não se possa dizer que eles tenham existido no mesmo sentido que Fernando Pessoa existiu.

É ao fim de uma complexa rede de operações que vemos surgir a funçãoautor, dando corpo à figura do autor tal como o conhecemos: origem da obra, responsável por ela e, na mesma medida, com direitos sobre ela. É também dessa individualização das ideias que passa a ser possível conceber a figura do escritor como um gênio, levado a escrever em razão de inspirações que lhe são próprias e interiores. Surge, assim, a concepção de um autor que está para seu texto como Deus está para os homens: onisciente, onipresente, onipotente.

\subsubsection{O círculo inventivo da obra e do autor}

Até o momento, procuramos mostrar algumas críticas à concepção de autor como uma instância natural. Com isso, buscamos apontar para o fato de que a unidade do autor não é evidente, e que, portanto, a compreensão da escrita como fruto de uma individualidade vem sendo problematizada consistentemente. Porém como podemos entender a relação entre obra e escritor sem recorrer à ideia de filiação? Vejamos o que dizem os escritores.

Em uma das muitas entrevistas que concedeu, Tezza afirmou: "Ao longo do tempo, fui percebendo o quanto o ato de escrever me modificou e me transformou. Essa é a 'maldição' - escrever é uma atividade sem retorno, de alto risco e sem a menor garantia de coisa nenhuma” (Tezza, 2013, p. 249). Essa fala embaça os limites entre autor e obra, em favor de uma ideia de coemergência: a obra não existe sem seu escritor, na mesma medida em que este somente existe uma vez que escreve a sua obra. Comentários de outros escritores atestam que Tezza não está sozinho. Clarice Lispector indica a possibilidade de transformação do escritor pela escrita ao afirmar que escrever "é perigoso porque nunca se sabe o que virá - se se for sincero. Pode vir o aviso de uma destruição, de uma autodestruição por meio de palavras" (Lispector, 1999, p. 183).

O círculo inventivo da escrita é este: antes de ser levada a cabo, a obra não existe em algum ponto obscuro da mente de seu escritor. Os substantivos "obra" 
e "escritor" dependem de um verbo que lhes permite emergir: escrever. É dessa prática que sujeito e objeto, autor e obra surgem (constituindo-se mútua e simultaneamente).

Em $A$ arte como experiência, Dewey (2010) afirma que, a todo momento, temos experiências, contudo elas normalmente são compostas por uma atenção distraída e dispersa, em que se sucedem fatos pouco interligados entre si e frequentemente interrompidos por motivos externos. Desse modo, elas não costumam compor "uma" experiência, que, para Dewey, é algo raro e com características específicas: ela tem uma unidade, mesmo que tenha sido longa. Ela é bem delimitada, distinguindo-se de tudo o que a antecede e do que a sucede; seu caráter emocional não vem se adicionar ao caráter ativo, mas ambos a compõem desde o seu princípio. "Uma" experiência é, portanto, dotada de qualidade estética. Isso não quer dizer que a experiência estética se limite ao campo da arte, mas pode ocorrer em qualquer domínio, como a vida cotidiana e mesmo o campo intelectual.

O autor afirma que, enquanto o termo "estético" normalmente designa a apreciação perceptiva, a palavra "artístico" geralmente refere-se a uma ação; a face ativa da arte seria tão marcante que muitos dicionários a definiriam como uma ação hábil. Entretanto é preciso haver um equilíbrio entre fazer e padecer para que haja experiência estética. Um excesso de ação resulta em pequenas experiências inteiramente superficiais, dispersas e confusas. Já o excesso de receptividade leva ao puro devaneio. Dewey defende que, na experiência estética, fazer e padecer não são momentos isolados e, tampouco, correspondem a pessoas diferentes (uma que age e outra que aprecia passivamente). Pelo contrário, toda experiência com caráter estético é composta tanto por um fazer quanto por um padecer.

Toda produção artística age sobre um material com vistas a produzir algo visível, audível ou tangível: tinta, palavras, mármore são transformados em quadros, livros e esculturas, respectivamente. Porém a ação habilidosa sem padecimento é um mero virtuosismo técnico. $\mathrm{Na}$ arte, a perfeição não pode ser definida em termos de execução, isto é, em termos da ação, pois demanda uma experiência de padecimento. A obra tem de ser feita "para" ser percebida, fruída; caso contrário, ela mobiliza nossa percepção para o simples reconhecimento. $\mathrm{O}$ artista deve incorporar a atitude do "percebedor" no momento em que trabalha. Desse modo, o primeiro leitor é, sempre, o próprio escritor. Nas palavras de Tezza, "Há sempre um leitor em cada frase que se escreve, um leitor atento no momento mesmo em que se escreve; este leitor não é exatamente o escritor, embora os olhos sejam da mesma pessoa" (Tezza, 2012, pp. 58-59). 
São as qualidades da obra que devem controlar a sua produção, de modo que o trabalho do artista é modulado pela percepção: o que é feito e o que é sofrido são continuamente sintonizados um com o outro. $\mathrm{O}$ processo artístico de criação, portanto, também é marcado pela inseparabilidade entre a feitura da obra de arte e sua apreciação. Ao longo de seu fazer, o artista é controlado pela relação que percebe entre o que já fez e o que ainda pretende realizar (Dewey, 2010). Por outro lado, a experiência perceptiva não é de mera passividade: esta não possibilitaria uma experiência completa, mas apenas um reconhecimento, percepção detida por um propósito, uma utilidade. O reconhecimento é cômodo; implica um retorno a esquemas previamente formados. $\mathrm{Na}$ experiência estética, a percepção corresponde a uma abertura ativa para a recepção. É uma espera atenta ou à espreita, muito diferente de um estado de passividade ou lassidão.

O escritor tem um duplo papel: é, simultaneamente, agente e fruidor. Ele tanto age sobre uma matéria quanto se abre ativamente para um encontro com aquilo que está sendo produzido. Os aspectos ativo e receptivo são inseparáveis e coexistem ao longo de toda a experiência estética. $\mathrm{O}$ escritor é aquele que age e padece ao produzir sua obra, visto que o obrar artístico também lança seus efeitos sobre ele (a partir de sua face perceptiva). No entanto é preciso enfatizar que isso não equivale a um simples interacionismo. Para as abordagens interacionistas, dois polos preexistentes atuam um sobre o outro, isto é, entram em uma relação de interação. O processo que descrevemos aqui é distinto deste. Trata-se de dois elementos que são segundos em relação à prática, isto é, ambos surgem de uma mesma ação, constituindo-se mutuamente a partir de uma mesma prática.

Conforme Dewey (2010) ressalta, o escritor deve se valer de uma observação constante ao longo do processo de produção. Desse modo, ele não precede e orienta a escrita, mas se constitui nela, igualmente. Da mesma maneira, Blanchot aborda as noções de agir e padecer ao tratar do par autor/leitor. Em $A$ parte do fogo (Blanchot, 2011a), ele afirma que esse par não é distribuído de modo definitivo e não corresponde a indivíduos, mas a "funções" que se exercem a um só tempo, pois cada um é os dois membros do par. Blanchot tenta ilustrar essa situação paradoxal vivida pelo escritor. Ele afirma que, embora a escrita surja como uma meta para o escritor, este não é capaz de preestabelecer, de forma precisa, quais passos dará para atingir essa meta. Estes somente se consolidam ao longo do processo de escrita. Esta questão parece fundamental: como tratar de um processo que envolve um escritor que, entretanto, não determina unilateralmente o seu fazer, mas que se constitui nesse mesmo movimento? Como compreender uma obra produzida por um escritor que se constitui ao mesmo tempo em que a escreve? 
Em uma de suas crônicas publicadas no Jornal do Brasil, Lispector afirma: "Antes havia uma diferença entre escrever e eu (ou não havia? não sei). Agora não mais. Sou um ser" (Lispector, 1999, p. 347). Da mesma forma, Blanchot (2011a) sustenta que o escritor não precede o processo de escrever, mas é constituído por ele e destaca que o escritor não é um gênio certo de si e de seus talentos. Ele necessita da obra, não apenas para se conscientizar de seus talentos, pois esse talento só existe a posteriori: antes de escrever, não se sabe se tem a capacidade de ser um escritor. Nesse sentindo, podemos entender o texto como o laboratório do escritor, como afirmado por Piglia (1994). Os possíveis dons do escritor, em si mesmos, não são nada. É, portanto, no próprio processo de escrever que o escritor emerge enquanto tal.

Essa mesma ideia aparece em Deleuze e Guattari (1993), para quem escrever não é apenas impor uma forma a uma matéria, mas também se deixar orientar pelos encontros que se tem com a própria escrita, por aquilo que se percebe da obra, ao fazê-la. Antes de concretizar a obra, ela não existe em algum lugar escondido, esperando para ser trazida da escuridão à luz. Ela precisa ser gestada e parida. E, nesse processo, qualquer projeto inicial de obra encontra obstáculos, sofre seus desvios, muda e, por vezes, torna-se irreconhecível. Como atesta Blanchot, antes de terminar o livro, é impossível para o seu escritor imaginar o que ele poderia vir a ser (Blanchot, 2011a).

Não apenas o projeto do texto se transforma: ao mesmo tempo em que escreve, o próprio escritor se cria e modifica. Não somente seu estilo e voz, mas, por vezes, também sua vida é transformada. A entrega à escrita altera o regime dos escritores: se escrevem melhor à noite, dormem de dia. Se precisam de calma, acordam antes de todos em sua casa. Para Blanchot (2011b), escrever muda-nos; e de um modo tão profundo que, mais do que escrever de acordo com aquilo que "somos", passamos a "ser" segundo o que escrevemos. Llosa (2008) parece concordar com isso, ao afirmar que escrever é uma maneira de viver, ocupando a existência do escritor, estendendo-se para além das horas de trabalho no texto, consolidando-se em uma atividade permanente. Mais ainda, para a autora Vigna (2014), quando escrevemos, nós nos modificamos e, quando se acaba um texto ou livro, o desconforto da escrita não se esvai, porque nós somos modificados, nossos relacionamentos pessoais se transformam, e até mesmo a maneira como nos vemos muda.

\subsection{Coemergência e criação literária}

Perguntar o que vem primeiro (obra ou o escritor) é colocar um falso problema. Trata-se aqui de círculo criador: antes da obra, não havia o escritor; porém, 
sem o escritor, não há a possibilidade da obra. Para compreender a dinâmica da criação, o conceito de coemergência se faz interessante. Varela, Thompson e Rosch (1993) retomam essa ideia, presente no budismo, para tratar de um processo de criação circular que, destituído de qualquer fundamento primordial, aponta para o mecanismo de coemergência. Com eles, podemos pensar que obra e escritor surgem de uma mesma ação, da prática da escrita. Uma vez iniciado, no entanto, o processo que cria tanto escritor quanto obra prossegue em uma relação de incessante cocriação. Essa relação ocorre por meio de perturbações mútuas, em que a feitura da obra é origem constante de desestabilizações para o escritor e para o próprio processo de escrita, e vice-versa.

Acompanhando Blanchot, vemos ainda que toda dúvida que o escritor tenha a respeito de si, de seus méritos ou de seus talentos não se resolve de outra maneira que não em ato. Ou seja, é preciso passar à ação e começar a escrever. É graças à obra que se torna um autor, isto é, sua existência como tal advém da obra. Não apenas ele a cria, mas ela o cria, de igual maneira (Blanchot, 2011a). Com base nessas reflexões a respeito da criação artística e literária, chegamos à ideia de coemergência entre o escritor e sua obra. Afinal, se a obra controla aquele que a escreve, se ela o constitui, se ele somente se torna um escritor por causa dela, como poderíamos continuar afirmando a existência de um autor como unidade soberana e prévia? Nesse sentido, a noção de produção de subjetividade é importante, pois permite que pensemos um processo de criação sem um polo que sirva como base explicativa, uma vez que o sujeito não deve ser entendido como o fundamento da criação, mas (e aí está o desafio) como um efeito dela (Kastrup, 2007).

Em $A$ arte do romance, Kundera (2009) compara metaforicamente o trabalho do romancista com o de quem desmonta sua própria vida, como uma casa, para criar um romance a partir de seus tijolos. Kundera afirma que os biógrafos estariam desfazendo o trabalho do escritor, ao tentarem retraçar cada tijolo do texto ao seu momento equivalente na vida. Para ele, quando o autor se torna mais importante que a sua obra, seu trabalho está sendo destruído. Como vimos, a importância dada à literatura pelo biografismo recai justamente sobre os tijolos mencionados por Kundera. O foco de tais estudos incide no significado de cada detalhe, cada palavra e na correlação possível entre eles e sua vida. Nessa análise, no entanto, deixam-se de lado as possíveis mudanças que a obra sofre à revelia de seu escritor. Mais ainda, ignoram-se os efeitos que a escrita produz sobre aquele que escreve.

Tezza (2011) também parece indicar que o romance produz linhas que fogem aos conteúdos meramente biográficos. Estes, embora possam ser usados, modificados, são deformados ao ponto de se tornarem irreconhecíveis. Desse 
modo, mesmo quando presentes na literatura, os elementos biográficos jamais são a simples transposição de uma situação real para uma linguagem. Como Hemingway pontuou claramente, "Faz-se algo por meio da sua invenção, algo que não é uma representação, mas uma coisa inteiramente nova, mais verdadeira do que qualquer outra coisa verdadeira e viva” (Hemingway, 2011, p. 92). A literatura é autônoma, isso quer dizer que ela não visa à representação de um mundo preexistente, mas à criação de um mundo. As obras literárias não são documentos psicológicos ou históricos, mas são textos que se dobram sobre si mesmos e se bastam a si mesmos. No que concerne à escrita literária, é preciso que nos afastemos da suposição de que existem um "eu" e um mundo a priori (Blanchot, 2011a).

$\mathrm{Na}$ tentativa de avançarmos na compreensão do processo de criação (que está para além e aquém das categorias de indivíduo ou sujeito), retomamos a noção de invenção (Kastrup, 2007). O processo de invenção parte de restos, de fragmentos de lembranças, recompondo-as para criar algo novo. O conceito de invenção escapa ao pressuposto representacionalista, visto que não se ancora nem em um objetivismo nem em um subjetivismo. Além disso, há uma diferenciação entre os termos "criatividade" e "invenção" (Kastrup, 2007). Na linguagem corrente, por vezes, nós nos referimos aos artistas como pessoas criativas. Entretanto, desde sua definição por Galton $(1869 ; 1883)$, a criatividade se refere a um processo de solução original de problemas já dados. Nessa medida, a criatividade é subsumida à inteligência. Esses estudos atingiram seu ápice entre as décadas de 1950 e 1960, mas se estendem até a atualidade, destacando-se as obras de Gardner (1996), acerca de inventores famosos, Piirto (1998; 2002; 2009), e Kaufman e Kaufman (2009), concernindo a criatividade na escrita, Simonton (1994), que investiga a relação entre criatividade e condições ambientais, Guilford (1971) e Torrance (1999), que procuram mensurar a capacidade criativa. Por outro lado, no processo de invenção, não há um problema fornecido de antemão. Trata-se de inventar o próprio problema, para em seguida solucioná-lo. Quando nos referimos ao processo de criação estamos falando de invenção e não de criatividade. Como afirma Tezza (2012), escrever não é solucionar um problema, mas criá-lo. Inclusive, entre os problemas criados, está a colocação da escrita como uma tarefa (tarefa esta que não existia anteriormente). Como bem destaca Lispector (1999), o impulso da escrita, ainda que sem tema, surge como uma força que a impele a agir, mesmo que não haja ninguém que a obrigue a escrever.

A literatura é marcada pela ruptura com aquilo que está estabelecido, comportando uma dimensão do inesperado, do incontrolável. Escrever é um trabalho de invenção de problemas tanto para o escritor quanto para a própria língua (que é levada ao seu limite). Todavia a invenção não é feita sem riscos. 
Como não há uma estrutura organizadora orientando esse processo, mas um constante encontro de forças, seu resultado é sempre imprevisível (seja com relação à obra, seja com relação ao próprio escritor) (Kastrup, 2007). Escrever, assim como viver, não é tornar concreta uma ideia que se tem a priori. Durante o processo, a ideia é constantemente reformulada, moldada e modificada por erros e acasos, e tal imprevisibilidade é um dos temas mais comentados pelos escritores ao falarem do seu processo de trabalho, dos personagens e dos próprios enredos de seus livros. Em uma entrevista concedida a Jean Stein, em 1956, Faulkner afirma que "sempre ocorre um ponto no livro em que os personagens se impóem e terminam o trabalho por si mesmos" (Faulkner, 2011, p. 19). Similarmente, Saramago (2003) conta que, com a escrita de um livro, sabe-se aonde se quer chegar, ainda que não se conheça o itinerário, pois "é o andar que faz o caminho" (p. 3). Esses escritores parecem indicar que, ao escrever, mesmo quando se tem um plano do que vai ser feito, o processo de criação toma rumos inesperados e leva a caminhos imprevistos.

Para Deleuze (2011), escrever é um processo de devir: de tornar-se outra coisa. Além de tornar-se escritor, como o afirma Blanchot, é também tornar-se estrangeiro em relação a si mesmo. Rolnik (1996) destaca o papel da arte como sendo mais do que a de projeção de conflitos internos: ela é um processo de invenção de si mesmo. Segundo Rolnik (1996), obra e artista se constituem um ao outro. A obra é produto do artista, mas é por meio dela que este se torna outro. Escrever não é um processo em que a escrita se soma a um $e u$ que a antecede, totalizando um escritor. É necessário que esse "eu" também padeça do processo, sofrendo desvios e transformações. Para Machado (2009), o que mais interessa a Deleuze, nesse ponto, é relacionar a linguagem e o devir. Devir não diz respeito a uma imitação, ou a tomar algo ou alguém como modelo. Esse conceito diz respeito à dupla captura que ocorre quando dois termos entram em relação e se alteram mutuamente. Como Deleuze afirma em Diálogos, "Não se trata também de dois termos que trocam de posição [. . .] Pois, à medida que alguém se torna, aquilo que ele se torna muda tanto quanto ele" (Deleuze \& Parnet, 1998, p. 24). Trata-se, portanto, de um processo que implica a modificação de todos os termos envolvidos. É por isso que falamos que o devir diz respeito a entrar em zonas de vizinhança ou de indiscernibilidade.

\section{A PSICOLOGIA, A ESCRITA E A CRÍTICA LITERÁRIA}

Ao investigarmos mais detidamente as formas habituais de compreender as relações entre autor e obra, nós nos deparamos com uma situação análoga no biografismo e em certas abordagens psicologizantes. O biografismo utiliza as 
informações biográficas sobre o autor como forma de desvendar o texto. Nas palavras de Proust (1988), a obra do crítico literário Sainte-Beuve consistia em "munir-se de todas as informaçóes possíveis sobre um dado escritor, em colecionar correspondência, em interrogar os homens que o conheceram" (p. 51) para, então, entendê-lo.

Analogamente, no psicologismo, a interpretação do texto serve como ferramenta de acesso às verdades intimas e secretas de seu autor. Em Dostoiévski e o parricídio, por exemplo, Freud (1928) procura elucidar a obra Os Irmãos Karamázov em fatos ou elucubrações acerca da vida de seu autor. Do mesmo modo, Jones (1970) interpreta passagens misteriosas de Hamlet a partir de interpretações feitas com base em sua biografia. Ambas as abordagens seguem uma mesma lógica: supõem que o autor antecede cronologicamente a obra, mantendo-se invulnerável a ela. Por antecedê-la, o autor, sua história pessoal, sua personalidade e seus segredos ganham relevo. Com base nesses dados, sustentase que poderíamos compreender melhor o texto, por sua vez, o texto poderia ajudar a clarificar aspectos desconhecidos da vida psíquica de seu autor. Trata-se de um argumento circular: com base nos dados acerca da vida (consciente ou inconsciente) do autor, poderíamos compreender melhor o texto; por sua vez, o texto poderia ajudar a clarificar aspectos desconhecidos da vida psíquica do seu autor.

Concluímos que certa tradição psicológica é análoga a outra, da crítica literária, uma vez que ambas parecem partir do pressuposto de que o autor é uma unidade prévia à obra e que esta é mero reflexo da história pessoal daquele que a escreveu. Com base em Varela, Thompson e Rosch (1993), propomos entender autor e obra como resultando de um processo de coemergência, surgindo de uma mesma prática: a de escrever literatura.

Psicologismos e biografismos desconsideram que alguém só se torna escritor quando escreve uma obra. O conceito de coemergência nos permite compreender o processo de criação literária sem recorrer à existência de um escritor como uma unidade preexistente que imprime uma forma desejada à matéria linguística. Pelo contrário, assim como a obra, o escritor também é fruto dessa prática, desse ato. Essa afirmação parece ser consonante com as falas de escritores, que afirmam que, em determinado momento, os personagens assumem o controle que, muitas vezes, não se sabe o fim de uma história ao começar a escrevê-la, ou que as próprias ideias vão se modificando ao longo do texto. O processo de criação dá origem tanto à obra quanto ao autor, visto que produz subjetividade, lançando seus efeitos sobre aquele que age, que escreve. Como Lispector (1999) afirmou: 
Quando não estou escrevendo, eu simplesmente não sei como se escreve. [.. .]. Sou a pessoa que mais se surpreende de escrever. E ainda não me habituei a que me chamem de escritora. Porque, fora das horas em que escrevo, não sei absolutamente escrever. Será que escrever não é um ofício? Não há aprendizagem, então? O que é? Só me considerarei escritora no dia em que eu disser: sei como se escreve (pp. 156-157). 


\section{REFERÊNCIAS}

Alves, M. A. (2014). O autor em cena: uma investigação sobre a autoria e seu funcionamento na modernidade. (Tese de Doutorado). Universidade Federal de Minas Gerais, Programa de Pós-Graduação em Filosofia, Faculdade de Filosofia e Ciências Humanas, Belo Horizonte.

Barthes, R. (1988). A morte do autor. In R. Barthes. O rumor da lingua. (pp. 65-70). São Paulo: Brasiliense.

Blanchot, M. (2011a). A parte fogo. Rio de Janeiro: Rocco.

Blanchot, M. (2011b). O espaço literário. Rio de Janeiro: Rocco.

Cabral, M. C. C. (2006). Encontros que nos movem: a leitura como experiência inventiva. (Tese de Doutorado). Universidade Federal do Rio de Janeiro, Programa de Pós-Graduação em Psicologia, Rio de Janeiro.

Capote, T. (2011). Entrevista concedida a Pati Hill. In Auden, W. H., Auster, P., Borges, J. L., Capote, T., Celine L. F., Faulkner, W., . . Levi, P. As entrevistas da Paris Review. (Vol. 1, pp. 37-57). São Paulo: Companhia das Letras.

Castle, G. (2007). The blackwell guide to literary theory. Malden: Blackwell.

Chartier, R. (1999). A aventura do livro: do leitor ao navegador. São Paulo: Editora Unesp.

Chartier, R. (2012). O que é um autor?: revisão de uma genealogia. São Carlos: EdUFSCar.

Deleuze, G. (2011). Crítica e clínica. São Paulo: Editora 34.

Deleuze, G., \& Guattari, F. (1993). O que é a Filosofia. Rio de Janeiro: Editora 34 .

Deleuze, G., \& Guattari, F. (2014). Kafka por uma literatura menor. Belo Horizonte: Autêntica, 2014.

Deleuze, G., \& Parnet, C. (1998). Diálogos. São Paulo: Escuta.

Dewey, J. (2010). Ter uma experiência. In J. Dewey. A arte como experiência. (pp. 109-141). São Paulo: Martins Fontes. 
Faulkner, W. (2011). Entrevista com W. Faulkner. Entrevista concedida a Jean Stein. As entrevistas da Paris Review. (Vol. 1, pp. 7-36). São Paulo: Companhia das Letras.

Ferreira, J. B. (2011). Do poema nasce o poeta. Rio de Janeiro: 7 Letras.

Ferreira, J. B. (2014). Sobrevivências, clandestinidades, lampejos: o trabalho vivo da criação literária. Fractal, Rev. Psicol., 26(n. esp.), 715-728.

Foucault, M. (2009). Ditos e escritos (Vol. III). In M. Foucault. Estética: literatura e pintura, música e cinema. Rio de Janeiro: Forense Universitária.

Foucault, M. (2013) A ordem do discurso. São Paulo: Loyola.

Freud, S. (1928/2014). Dostoievski e o parricídio. In S. Freud. Escritos sobre literatura. (pp. 9-31). São Paulo: Hedra, 2014. (Publicado originalmente em 1928).

Gagliardi, C. (2010). O problema da autoria na teoria literária: apagamentos, retomadas e revisões. Estudos Avançados, 24(69), 285-299. Recuperado a partir de http://www.scielo.br/scielo.php?script=sci_arttext\&pid=S0103$40142010000200018 \& \operatorname{lng}=$ en $\&$ nrm $=$ iso

Galton, F. (1869). Hereditary genius. New York: Macmillan.

Galton, F. (1883). Inquiries into human faculty. London: Macmillan.

Gardner, H. (1996). Mentes que criam. Porto Alegre: Artes Médicas.

Guilford, J. P. (1971). Potentiality for creativity. In J. C. Gowan, \& E. P. Torrance (Orgs.), Educating the ablest. (pp. 203-208). Ithaca: Peacock.

Gurgel, V. (2015). A escrita Literária: a coemergência da obra e do autor. (Dissertação de Mestrado). Universidade Federal do Rio de Janeiro, Programa de Pós-Graduação em Psicologia, Rio de Janeiro.

Helson, R. (1977). The creative spectrum of authors of fantasy. Journal of Personality, 45, 310-326.

Hemingway, E. (2011). Entrevista concedida a George Plimpton. In Auden, W. H., Auster, P., Borges, J. L., Capote, T., Celine L. F., Faulkner, W., . . Levi, P. As entrevistas da Paris Review (Vol. 1). São Paulo: Companhia das Letras.

Jones, E. (1970). Hamlet e o complexo de Édipo. Rio de Janeiro: Zahar. 
Kastrup, V. (2007). A invenção de si e do mundo: uma introdução do tempo e do coletivo no estudo da cognição. Belo Horizonte: Autêntica.

Kaufman, J. C. (2002). Dissecting the golden goose: components of studying creative writers. Communication Research Journal, 14(1), 27-40.

Kaufman, S. B., \& Kaufman, J. C. (Orgs.). (2009). The psychology of creative writing. New York: Cambridge University Press.

Kundera, M. (2009). A arte do romance. São Paulo: Companhia das Letras.

Lispector, C. (1999). A descoberta do mundo. Rio de Janeiro: Rocco.

Llosa, M. V. (2008). Cartas a um jovem escritor. Rio de Janeiro: Elsevier.

Machado, R. (2009). Deleuze, a Arte e a Filosofia. Rio de Janeiro: Zahar.

Marías, J. (2011). Entrevista concedida a Sarah Fay. In Auden, W. H., Auster, P., Borges, J. L., Capote, T., Celine L. F., Faulkner, W., . . . Levi, P. As entrevistas da Paris Review. (Vol. 1, pp. 419-460). São Paulo: Companhia das Letras.

Pantaleão, M. I. C. (2013). Da paisagem literária à escrita inventiva. (Tese de Doutorado). Universidade Federal do Rio de Janeiro, Programa de PósGraduação em Psicologia, Rio de Janeiro.

Pessoa, F. (1974). Obras em prosa. Rio de Janeiro: José Aguilar.

Piglia, R. (1994). O laboratório do escritor: ficção e política na literatura argentina. São Paulo: Iluminuras.

Piirto, J. (1998). Understanding those who create. Scottsdale: Great Potential.

Piirto, J. (2002). My teeming brain: understanding creative writers. Creskill: Hampton.

Piirto, J. (2009). The personalities of creative writers. In S. B. Kaufman, \& J. C. Kaufman (Eds.), The psychology of creative writing. (pp. 3-22). New York: Cambridge University Press.

Proust, M. (1988). Contre sainte-beuve: notas sobre crítica e literatura. São Paulo: Iluminuras.

Rolnik, S. (1996). Lygia Clark e o híbrido arte/clínica. Caosmose.net. Recuperado a partir de http://caosmose.net/suelyrolnik/pdf/Artecli.pdf 
Saramago, J. (2003, $1^{\circ}$ outubro). Ideias claras, escrita clara. Entrevista concedida a Paola Gentile. Nova Escola. Recuperado a partir de http://revistaescola.abril.com.br/lingua-portuguesa/pratica-pedagogica/ideiasclaras-escrita-clara-423611.shtml

Simonton, D. K. (1994). Stimulating creativity: individual procedures. (Vol. 1). Nova York: Academic Press.

Storr, A. (2013). A dinâmica da criação. São Paulo: Benvirá.

Tezza, C. (2011). Beatriz. Rio de Janeiro: Companhia das Letras.

Tezza, C. (2012). O espirito da prosa: uma autobiografia literária. Rio de Janeiro: Record.

Tezza, C. (2013). Cristóvão Tezza. In J. Castello, \& S. Caetano (Orgs.), O livro das palavras. (pp. 246-267). São Paulo: Leya.

Torrance, E. P. (1999). Torrance test of creative thinking: norms and technical manual. Besenville: Scholastic Testing Service.

Varela, F., Thompson, E., \& Rosch, E. (1993). The embodied mind. Cambridge: MIT Press.

Vigna, E. (2014, janeiro). Entrevista: Elvira Vigna. Entrevista concedida ao Paiol Literário. Rascunho, 165. Recuperado a partir de http://rascunho.com.br/elvira-vigna/ 